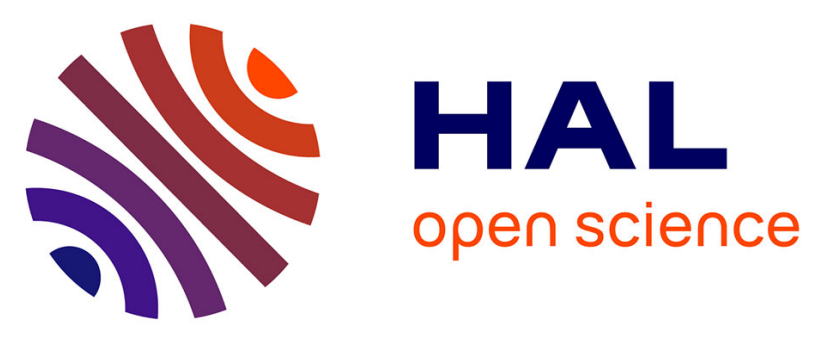

\title{
Process versus personal accidents within sociotechnical systems: Loss of control of process versus personal energy?
}

Sylvie Leclercq, Gael Morel, Christine Chauvin

\section{To cite this version:}

Sylvie Leclercq, Gael Morel, Christine Chauvin. Process versus personal accidents within sociotechnical systems: Loss of control of process versus personal energy?. Safety Science, 2018, 102, pp.60 67. 10.1016/j.ssci.2017.10.003 . hal-01617044

\section{HAL Id: hal-01617044 \\ https://hal.science/hal-01617044}

Submitted on 20 Nov 2017

HAL is a multi-disciplinary open access archive for the deposit and dissemination of scientific research documents, whether they are published or not. The documents may come from teaching and research institutions in France or abroad, or from public or private research centers.
L'archive ouverte pluridisciplinaire HAL, est destinée au dépôt et à la diffusion de documents scientifiques de niveau recherche, publiés ou non, émanant des établissements d'enseignement et de recherche français ou étrangers, des laboratoires publics ou privés.

\section{(1) (1) $\$$}

Distributed under a Creative Commons Attribution - NonCommercial - NoDerivatives $\mid 4.0$ 
PROCESS VERSUS PERSONAL ACCIDENTS WITHIN SOCIOTECHNICAL SYSTEMS: LOSS OF CONTROL OF PROCESS VERSUS PERSONAL ENERGY?

BY SYLVIE LeCLERCQ ${ }^{1}$, GAEL MOREL ${ }^{2} \&$ Christine CHAUVIN ${ }^{2}$

1. Institut National de Recherche et de Sécurité

1 rue du Morvan - CS 60027 - 54519 Vandœuvre cedex - France sylvie.leclercq@inrs.fr

2. Université de Bretagne Sud, Labsticc, UMR 6285

Rue Armand Guillemot - BP 92116 - 56321 Lorient Cedex - France

gael.morel@univ-ubs.fr - christine.chauvin@univ-ubs.fr

Corresponding author

Sylvie Leclercq

Institut National de Recherche et de Sécurité

1 rue du Morvan - CS 60027 - 54519 Vandœuvre cedex - France

sylvie.leclercq@inrs.fr 
Abstract. Process safety and personal safety are often distinguished in literature and practice despite an acknowledged advantage in their integration. Degree of damage and type of hazard are advanced as factors that distinguish process and personal accidents. A damage production model based on a hazard systematically characterised by an energy is proposed. This distinguishes energies external to the victim and specific to process operation from energy related to the victim's movements. This development is based on six accident cases, of which three are consistent with common representations of a process accident and three of a personal accident. They are identified in the sea fishing and hospital sectors. This ensures broad coverage of different hazard types and resulting damage. The proposed model is capable of formalising the coexistence of hazards (i.e. energies) that are fundamentally different. It highlights different kind of energies to be controlled by a sociotechnical system. Our model also reveals practical difficulties of protecting an exposed target in relation to the type of energy causing damage. It is a tool useful for integrating control of process and personal energies, combining the aims adopted for managing process and personal safety.

KEYWORDS: Accidents - Energies - Sociotechnical systems - Models - Safety

\section{INTRODUCTION}

A distinction between process and personal safety is made in practice and in the literature (Hopkins, 2009; Grote, 2012) despite the advantage expressed for their integration (Fahlbruch and Wilpert, 2001; Carayon, Hancock et al., 2015). Type of hazard and resulting damage are what clearly distinguish process safety from personal safety (Hopkins, 2009). It is our hypothesis that a model formalizing the difference between process and personal accident, in term of hazard, could represent an advance towards integrating these process and personal safety.

Hazard is the element through which a risk is apprehended and its identification is the starting point of risk management. The hazard is characterised differently if it is a process accident or a personal accident. For example the bowtie model-based generic representation of an accident may be used for hazardous substance risk management under the Seveso III directive (Bragatto et al., 2015). In this representation, hazard appears as the "hazard top event", one of whose modes is "overflow of chromic solutions into containment basin". In this case, the hazard top event refers to loss of control of a chemical process. The bowtie model may also 
be used as a tool for comparing occupational accidents based on their seriousness (Bellamy, 2015). In this representation, hazard appears as the "accidental release of the hazard agent" whose modes mostly refer to how the injury is produced (e.g. contact with electricity, extreme muscular exertion or contact with machine moving parts) or else to loss of control of the victim's movement (e.g. fall on the level). We note a different characterisation of the hazard when process or occupational accidents are concerned. We also note that in occupational accidents, hazard categories are neither mutually exclusive nor mutually consistent. Indeed, some injuries can result from contact with machine moving parts which can itself result from a fall on the level. In the case of a fall on the level, the injury can be caused by contact with the floor or an object in the physical environment. Why are we not consistent with other contact-related hazard categories by considering "contact with the floor" instead of "fall on the level"?

In short, the polysemic nature of the hazard concept leads to adopt labels of different natures to express the hazard. These items are neither comparable, nor always mutually consistent. This paper proposes an harmonized characterisation of hazard for every accident occurring in a sociotechnical system, whether it is a personal accident or a process accident. We develop a model of accident damage production - the very final stage of damage genesis that involves the hazard concept - based on a common energy-based hazard characterisation. This model focuses on the two types of energy involved in the loss of control with which the sociotechnical system must cope: energies specific to process operation and energy related to workers's movements.

This paper is divided into three sections. The first one examines the current status of the contents of databases, which capitalise on different accident types in sociotechnical systems. It allows to highlight the issue related to each kind of safety and the fuzzy perimeter between process and occupational accidents. It also emphasizes different types of hazard that are present and managed in these systems, before going on to examine the hazard concept. The second section of the paper describes development of a damage production model using a set of 6 accidents embracing the different types of hazard encountered in sociotechnical systems. In this model, hazard is systematically characterised by an energy. Finally, the third section of the paper is a discussion on safety management based on the developed model and on the literature. 


\section{STATE OF THE ART}

\subsection{PROCESS ACCIDENTS/PERSONAL ACCIDENTS: ISSUES, PERIMETERS AND HAZARDS}

Examining the contents of databases, which capitalise on different accident types in sociotechnical systems, is a way of assessing the risks present and managed in these systems and of taking up the challenge represented by their prevention. We note that these accidents are covered by different surveys based on the targets jeopardised by them (workers, provided service beneficiaries, environment, installations, etc.) and on the type of declaration required by the system, (e.g. when work accidents occur).

The ARIA (Analyse Recherche et Information sur les Accidents) database was developed by BARPI (Bureau d'Analyse des Risques et Pollutions Industriels ${ }^{1}$ ) to record process accidents occurring at "Installations Classées Pour l'Environnement" (ICPE), environmentally classified facilities in France, and those involving transport of hazardous materials, gas distribution and domestic usage, mines, quarries and hydraulic structures. These are accidents that have caused (or could have caused) damage to targets such as company installations, the environment, surrounding populations and/or company personnel. Such accidents result from loss of control of hazardous materials or technical equipment, so the term process is here used to characterise technical equipment and hazardous materials and does not include the associated personnel. Data on French accidents listed on the ARIA database come from different sources, in particular, public authorities, the press and sometimes professional bodies. Moreover, a number of international organisations also provide information on accidents outside France. Finally, the ultimate aim of creating the ARIA database was to ensure that prevention could benefit from experience feedback.

With regard to occupational accidents, databases have been drawn up using compulsory declarations made by companies for each employee injured at work; the ultimate purpose of these surveys being to ensure redress on the part of the victims.

We note that these surveys are performed neither uniformly nor exhaustively. On the one hand, there are overlapping areas in their records: for example, an ARIA database accident causing so-called major damage, which has inflicted bodily injuries on several workers, appears as many "personal accidents at work" database entries as there are worker victims. On the other hand, an accident revealing loss of process control, whose resulting damage is qualified as minor and limited to the company, is not systematically listed on a process

\footnotetext{
${ }^{1}$ Industrial hazard and pollution analysis unit at the French Sustainable Development Ministry's General Directorate for Risk Prevention
} 
accident database. It will appear on the database that lists occupational accidents in the form of as many events as there are victims among the workers. It should also be stated that the ARIA database does not only include accidents that have occurred in France and that the database consolidating occupational accidents at companies belonging to the French general social security system only covers approximately $75 \%$ of French employees. Despite these limitations, it is still interesting to examine the frequencies of the accidents recorded on these two databases. Since 1992, the ARIA database has been enriched with a total of 43,976 accidents and incidents. 37,586 of these are in France, of which 26,368 involve classified facilities. 899 accidents were recorded in 2013; each of these gave rise to an intervention by public emergency services and a declaration to the French classified facility inspectorate. These accidents had consequences, in particular environmental in 251 cases and human in 160 cases. There were 7 fatalities, 19 serious injured victims and 158 injured victims. At the same time, over 600,000 occupational accidents with days lost, over 500 fatal occupational accidents, over 40,000 occupational accidents leading to permanent disability and over $18,000,000$ days lost due to temporary disability are recorded each year for companies belonging to the French general social security system employing more than 18 million people nationally (CNAMTS data). Around a quarter of these accidents resulted in injuries caused by an element, with which any contact or closeness will cause injury (high voltage source, corrosive chemical, certain moving parts of a machine, etc.). The remaining threequarters resulted in injuries prompted by falling more or less from a height, collisions, jamming, elements that give way when the person exerts actively forces on them or appearance of pain, especially during handling operations (Leclercq, Cuny-Guerrier et al. 2015). These accidents most frequently reflect the victim's loss of control of his/her movement without involving systematically hazardous materials or technical equipment in the production of injury.

The nature of the various risks to be confronted by a sociotechnical system is strongly dependent of the activities developed by these systems. While the so-called "high risk" only exists at certain companies, the risk of an accident caused by movement disturbance is effectively present in all sociotechnical systems and can affect directly both company workers and provided service beneficiaries. Having said this, every sociotechnical system, whatever it may be, has to confront accident risks that involve hazards of different types affecting different targets. These different hazards are distinguished and sometimes qualified as process hazard or personal hazard, the latter causing most injuries and fatalities (Hopkins, 2009). 


\subsection{HAZARD CONCEPT}

The October 2005 glossary of technological risks defines a hazard as "an intrinsic property of a substance (butane, chlorine, etc.), a technical system (pressurizing gas, etc.), a provision (elevation of a load), a body (microbes), etc., likely to cause damage to a "vulnerable target"'. The International Risk Governance Council (IRGC, 2005) stated that "Hazards describe the potential for harm or other consequences of interest. They characterize the inherent properties of the risk agent and related processes". Kjellen (2000) adopts the following definition of hazard: "a source of possible injury to personnel or damage to the environment or material assets".

Hazard is therefore frequently characterised by an intrinsic property of an element/agent likely to cause damage to an exposed target, which can be a human being and/or the environment. In most cases, these definitions refer, explicitly ${ }^{2}$ or not, to an element that is external to the target and recognizable as harmful when assessing a priori the risk. For example, when mapping hazards, Koehler and Volkens (2011) project the intensity or concentration of a chemical agent onto a two-dimensional floor plan or workplace layout. In this case, the hazard is a chemical agent (a chemical energy carrier), which is external to the target and identified a priori as a clear possible cause of damage, if exposure occurs.

On the other hand, Rasmussen and Svedung (2000) consider hazard sources as "physical phenomena that may lead to damage, if not adequately controlled".

Other definitions of hazard are also adopted in the context of occupational accidents, in which the target and the negative outcome are a human being and an injury respectively. Unlike the previous definitions, these refer to the fact that hazards can originate from humans or objects, both energy carriers (kinetic, potential, thermal, chemical or radiant) that can be harmful to humans (Hoyos, 1980). The expression "physical ergonomic hazard" is also used to qualify work activities and/or workplace conditions that create biomechanical stress for the workers (Tak and Calvert, 2011).

\footnotetext{
${ }^{2}$ In the International Classification of External Causes of Injury (ICECI, 2004) for example
} 


\section{DEVELOPMENT OF A DAMAGE PRODUCTION MODEL USING SAME ENERGY- BASED HAZARD CHARACTERISATION}

\subsection{METHOD}

\subsubsection{A SET OF 6 CASES OF ACCIDENTS IN 2 DIFFERENT SOCIOTECHNICAL SYSTEMS: SEA FISHING AND HOSPITAL CARE}

The developed damage production model is intended to be generic and not specific to one given activity sector. The set of 6 accidents was composed from the literature and from databases. The underlying aim was to best cover the possible types of hazard and the resulting degrees of damage. Two very different activity sectors were considered for this purpose. Three of the six accidents occurred in the sea fishing sector and three others in the hospital care sector. These accidents were either caused by losing control of a process, leading to major damage ${ }^{3}$ or damage limited to the organisation, or could be characterised as personal and be caused by the victim losing control of his/her movement. Personal accidents affect company workers or beneficiaries of a provided service.

The developed model represents the damage production, i.e. the very final stage of damage genesis that involves the hazard concept. Only this final stage is represented without considering factors leading to the loss of control.

\subsubsection{ENERGY-BASED HAZARD CHARACTERISATION FOR EACH ACCIDENT CASE}

As early as 1961, Gibson represented production of a bodily injury as energy (electrical, chemical, mechanical, etc.) absorption by a part of the body (Gibson 1961). In the generic accident models, we often note this notion of energy release to initiate damage production (e.g. Kjellen, 2000; Bellamy et al., 2013). We therefore systematically characterise the hazard by its damage causing energy in our proposed model. However, this characterisation creates a difficulty in formalising the type of energy in some accident cases. In the process accident quoted by Hopkins ${ }^{4}$ (2009), it is loss of control of chemical energy (toxic substances) that causes the human, physical and/or environmental damage. In a road accident, loss of vehicle

\footnotetext{
${ }^{3}$ These accidents are associated with so-called high risk processes (more in terms of seriousness than frequency - cf. Section 2.1), when they are likely to cause release of a considerable amount of energy. This produces damage affecting not only the organisation and its employees, but also the external environment and/or surrounding populations.

${ }^{4}$ Typical process safety incidents include escape of toxic substances and release of flammable material which may or may not result in fire or explosions.
} 
control releases kinetic energy, which increases as the vehicle speed increases and this release causes damage that is also human, physical and/or environmental. Kjellén (2009) cites other accidents, such as falls and "caught in or between machinery", as involving specific energy types, although he does not detail these. Faced with the question "In what energy class belongs cutting oneself in the hand?", Rasmussen and Svedung (2000) discard hazard taxonomy based on exclusive classification of energy forms that could harm people. They indeed adopt a more pragmatic classification of hazard sources based on a number of well defined, bounded sources and a further category entitled "others, mixed". To characterise systematically the hazard based on energy, we referred to the accident model with movement disturbance developed by Leclercq, Monteau et al. (2010) (illustrated in Figure 1). This model is not generic. It only represents certain personal accidents: those in which the victim loses control of his/her movement. This model indicates that, in the above case of a person sustaining a cut on the hand when manipulating a cutting implement, injury is directly caused by the person's movement energy combined with the cutting implement characteristics (shape, deformability). The hazard would therefore be composite and the energy that proves harmful in cases of movement disturbances when working (collision, trip, slip, twist, etc.) is the energy of worker movements (Leclercq 2016).

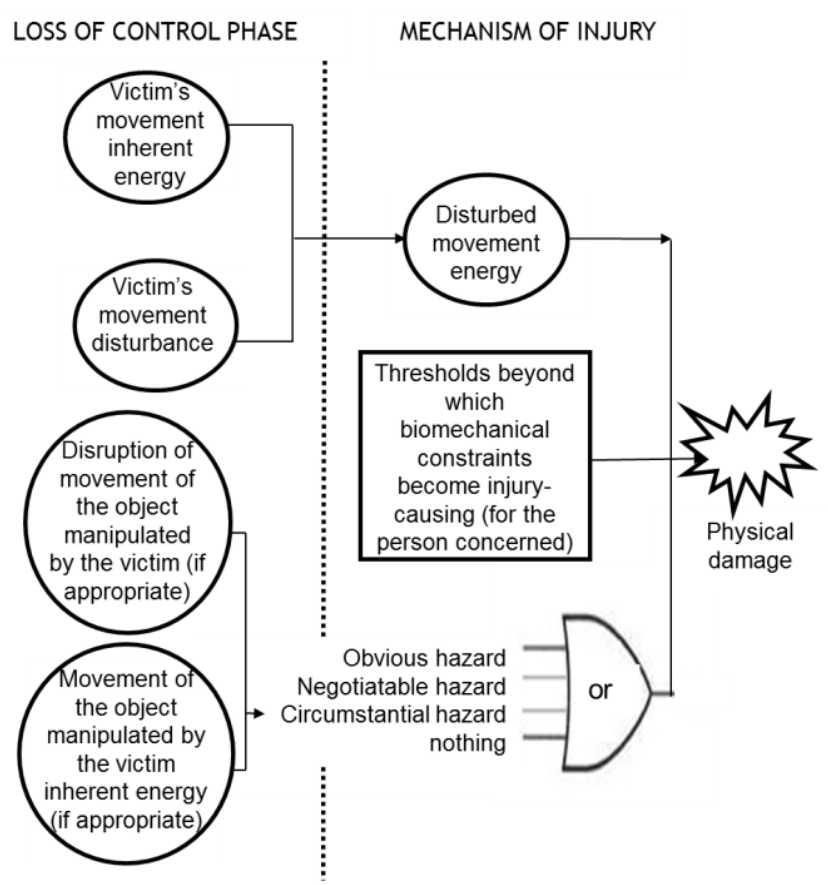

Figure 1. Model of damage producing mechanism for an accident with movement disturbance according to Leclercq (2016) 
We therefore characterise the hazard for each accident by the energy, whose control has been lost. We distinguish the energies external to human (process energy) from human's movement energies (personal energy).

\subsubsection{REPRESENTING DAMAGE PRODUCTION FOR EACH ACCIDENT CASE}

We represent damage production by instantiating it for each of the 6 accident cases using the generic accident model developed by Kjellén (2000) (illustrated in Figure 2). In this model, the damage is represented as the result of a loss of control, which causes energy to be absorbed by an exposed target. In Figure 2, the length of the arrow conveying this energy represents the damage production time. Damage ceases to be produced when the energy absorption stops. For each accident, we identify a posteriori the targets that were exposed at the moment control was lost and the relevant type of damage producing energy. We then represent damage production by an arrow conveying the energy; the beginning and end of this arrow being associated with the exposed targets and the end of damage production (formalised by the damage itself) respectively.

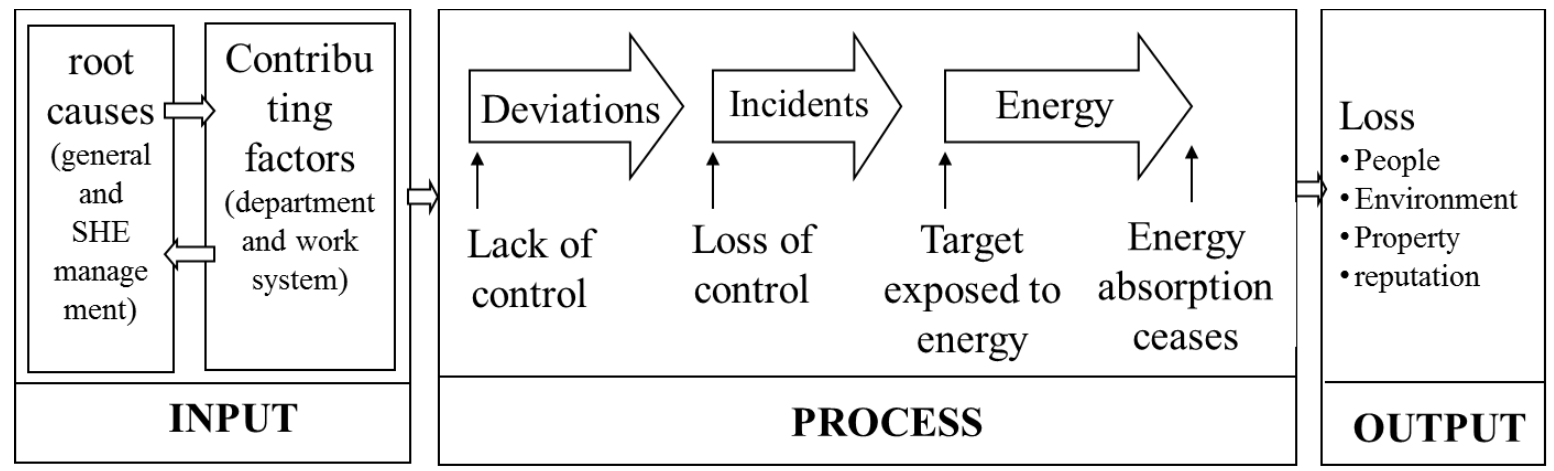

Figure 2. Generic accident model (Kjellen, 2000)

\subsection{RESULTS}

Table 1 includes six accidents, which occurred in the sea fishing and hospital care sectors. For each accident, we detailed: 1. An extract of the accident account describing damage production; 2 . The damage targets; 3 . The energy producing the damage. Accidents 1,2 and 4 are consistent with common representations of a process accident. The damage affected the boat, the boat and its skipper and the patients treated respectively. In each case, the energy producing the damage was specific to the process (boat movement energy, energy subsequent to an explosion on board the boat and radioactive energy used to treat the patients). Accidents 
3, 5 and 6 are consistent with common representations of a personal accident. The damage affected a seaman, a nurse and a patient respectively. The energy producing this damage was either process-specific (boat movement energy) or victim movement energy (arm movement energy, movement energy when falling). 


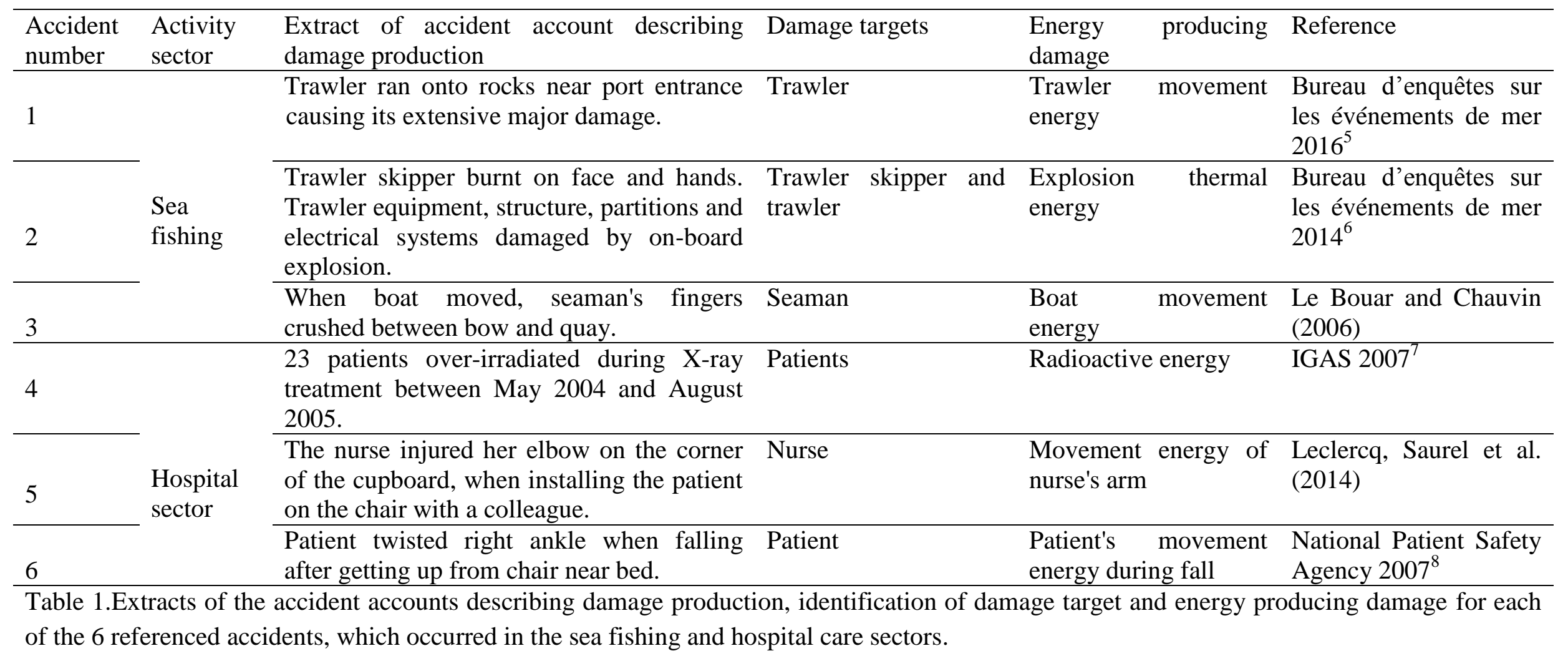

\footnotetext{
${ }^{5} \mathrm{http}: / /$ www.bea-mer.developpement-durable.gouv.fr/IMG/pdf/BEAMER-FR_CINTHARTH_2015.pdf ${ }^{6} \mathrm{http} / / / \mathrm{www}$.bea-mer.developpement-durable.gouv.fr/IMG/pdf/BEAMER-FR_CINTHARTH_2015.pdf

${ }^{7} \mathrm{http} / / / \mathrm{www}$. ladocumentationfrancaise.fr/var/storage/rapports-publics/074000198.pdf

${ }^{8}$ http://www.nrls.npsa.nhs.uk/EasySiteWeb/getresource.axd?AssetID=61390\&
} 
Table 2 includes the damage production representations for each of the 6 accidents using the elements identified in Table 1. Process specific energies are represented by of the human is represented by as follows: $\mathcal{W}$ for the workers, $\mathcal{W}$ for the surrounding populations and the beneficiaries of the provided service, 漹for equipment and company facilities and $r$ the environment. 


\begin{tabular}{|c|c|c|}
\hline $\begin{array}{l}\text { Activity } \\
\text { sector }\end{array}$ & $\begin{array}{l}\text { Accident } \\
\text { number }\end{array}$ & Representation of damage production \\
\hline & 1 & 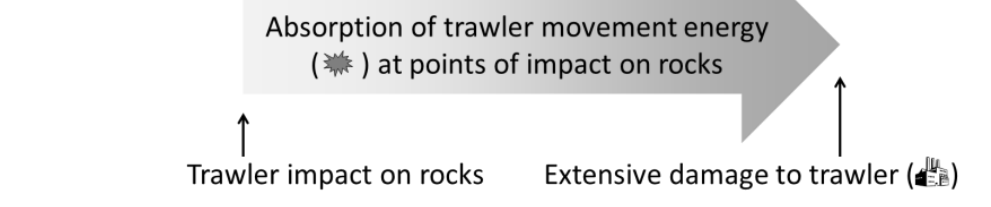 \\
\hline $\begin{array}{l}\text { Sea } \\
\text { fishing }\end{array}$ & 2 & 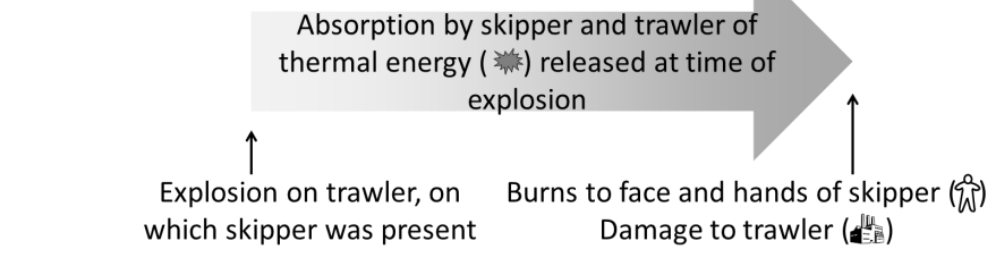 \\
\hline & 3 & $\begin{array}{l}\text { Absorption of boat movement energy ( } \\
\text { by seaman's fingers during crushing }\end{array} \uparrow_{\text {Start of crushing of seaman's fingers }}^{\uparrow}$ \\
\hline \multirow{3}{*}{$\begin{array}{l}\text { Hospital } \\
\text { sector }\end{array}$} & 4 & 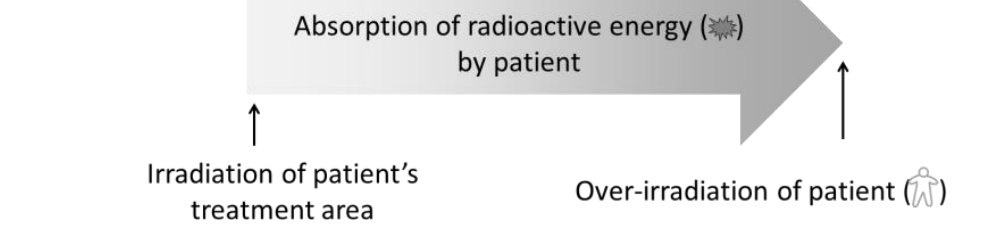 \\
\hline & 5 & 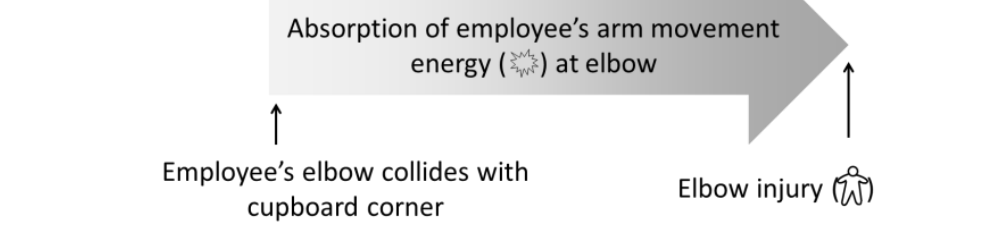 \\
\hline & 6 & 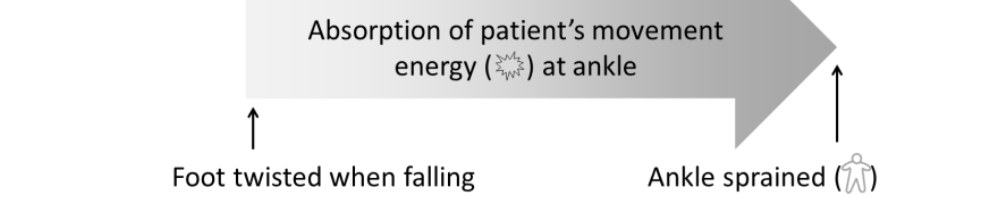 \\
\hline
\end{tabular}

Table 2. Representation of damage production for each of the 6 accidents

Figure 3 gives a model of damage production from the loss of control of energy characterising the hazard for any accident occurring in socio-technical systems. It distinguishes cases based on type and quantity of energy producing the relevant damage (energy external to a human and energy conveyed by a human). It should be recalled that we are not highlighting, in this 
model, the differences in the causes upstream in the damage genesis according to the type of damage producing energy. In personal and process accidents, these causes are referred to in the discussion on the proposed model and the literature.

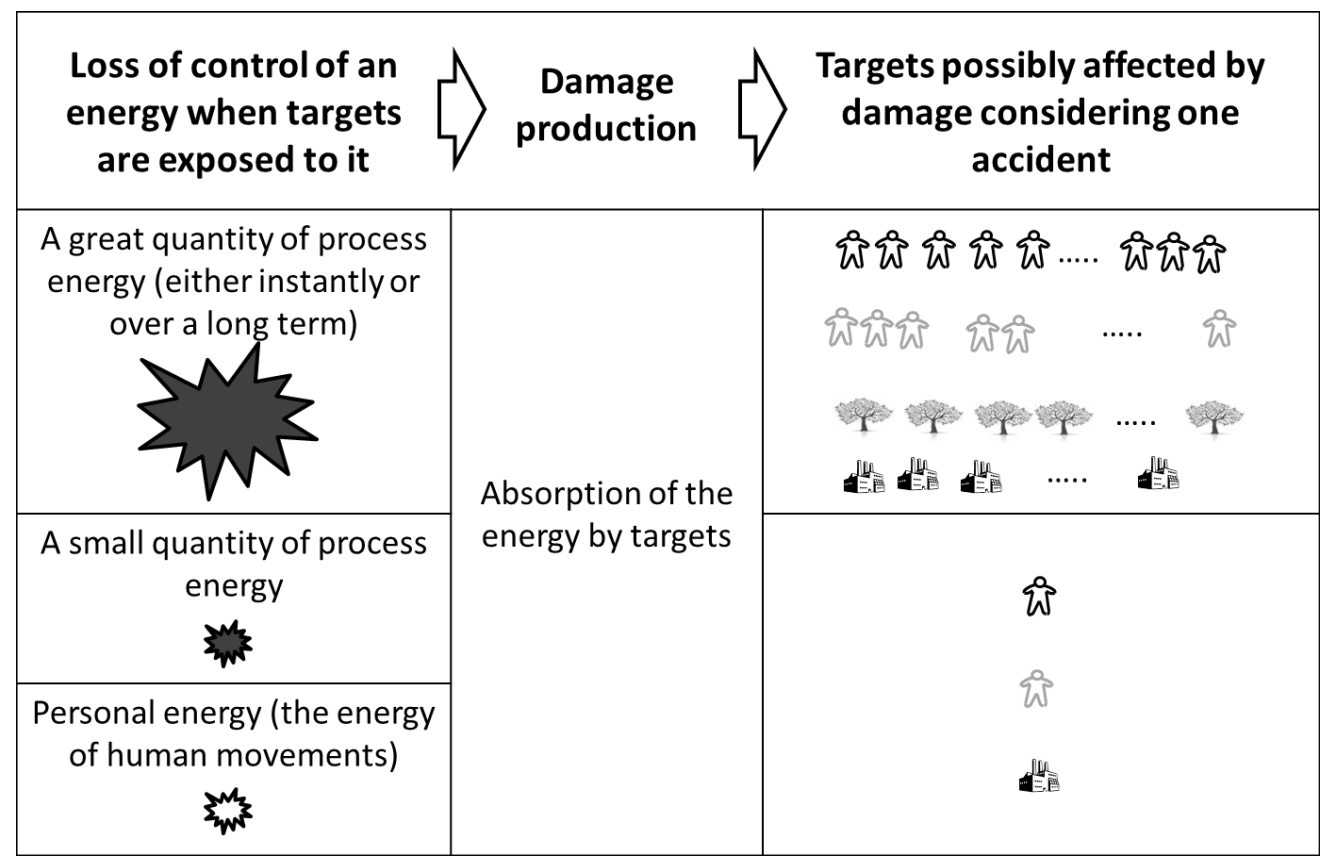

Figure 3. Model of damage production from loss of control of energy characterising the hazard in any accident occurring in socio-technical systems. Process specific energy is represented by targets are represented as follows: $W_{\text {for workers, }}$ for surrounding populations and beneficiaries of a provided service, for equipment and company facilities and the environment.

\section{DISCUSSION}

4.1. PROCESS AND PERSONAL ACCIDENTS : A QUESTION OF QUANTITY BUT, ABOVE ALL OF ENERGY TYPE

The proposed model formalises the coexistence of hazards/energies of fundamentally different nature. Accidents with a victim (e.g. cases 3, 5 and 6 above) may involve energy external to man but it is more often human movement energy that produces the damage (cf. Section 2.2.). Accident 4, featuring radioactive energy, involved several patients. An accident featuring radioactive energy and causing one victim patient is also possible. However, would 
this accident be considered a personal accident in the same way as accident 6 with a victim patient? It appears likely that qualification of an accident as process or personal is determined not only by the quantity of energy that produced the damage and thus by the amount of damage, but also by a risk (suggested by the energy type involved) greater than that which manifested itself through the accident concerned. Such a risk always involves process energy. The accidents included on the ARIA database (cf. Section 2.1.) are effectively those that caused (or could have caused) damage affecting multiple targets.

Unlike accidents causing major damage, loss of a person's movement control usually only threatens that person himself or herself, even though that person may lose his or her life. Such accidents are therefore undeniably personal accidents due to the type of energy producing the damage and due to the damage itself. Falls, collisions and other accidents caused by movement disturbance are moreover the examples most frequently quoted to illustrate personal accidents. Persons at work or outside work are very often in movement and this creates a more or less high risk of movement disturbance depending on the conditions governing movement execution. This almost permanent exposure may explain the high frequency of accidents triggered by movement disturbance. These accidents can exhibit all degrees of seriousness depending on the conditions governing movement execution and the potential consequences of movement disturbance (working at height or sharp edges with which there is accidental contact). Considering the lethality nature of hazards as well as exposure leads us to note that it is not the most lethal hazards which cause the most deaths (Bellamy, 2015).

\subsection{HAZARDS CHARACTERISED BY ENERGY REVEAL OCCUPATIONAL ACCIDENTS OFTEN OVERLOOKED BY RISK ASSESSMENT}

Figure 1 illustrates that, in accidents triggered by movement disturbance, the hazard is composite in the sense that two elements contribute directly to the injury production. These are worker movement energy and an element in the physical environment with which there is contact following movement disturbance. It seems that in such accidents, the hazard is usually identified as the major direct cause of injury, obscuring the second cause with a more minor role in injury occurrence. "Fall from height" or "fall on the level" suggests a hazard as being the kinetic energy and the element on which the victim falls is therefore neglected. "Contact with moving parts of machine" or "contact with sharp edges" suggests a hazard associated with elements in the physical environment, the energy of the victim's movement being neglected. In connection with other injuries sustained by children falling in playgrounds, 
Runyan (2003) identified explicitly playground equipment and devices (not the kinetic energy accumulated during the fall) as the accident-causing "agent/vehicle" (i.e. hazard). Systematic characterisation of hazard as an energy can therefore help us to highlight the very many occupational accidents that are usually not revealed in risk assessment. These involve injuries caused by movement disturbance when working (e.g. collision/jamming/twisting) that are not impacts against an element identified as "hazardous/harmful" and do not result from a loss of balance, when moving, or when working at height. Yet, these accidents are very frequent and are often serious. Indeed, they represented more than $20 \%$ of occupational accidents in Quebec, Canada from 2005 to 2007, resulting in 51 days lost on average (Gauvin, Lan et al. 2015).

\subsection{PRACTICAL DIFFICULTIES IN PROTECTING THE TARGET}

Using Gibson's energy model (Gibson, 1961), Haddon derived 10 prevention/protection strategies involving the energy source (modification, quantity limitation, etc.) by placing barriers between it and the victim. He also developed strategies involving the victim himself or herself (increasing his/her resistance, etc.) (Haddon 1973). Insertion of different types of barrier also represents a method of preventing process accidents (Hollnagel 2004; Hollnagel 2008).

If we examine Haddon's strategies (cf. Figure 4), we see that they are appropriate when bodily injury is caused by energy external to man and which proves to be harmful when close or in contact (high voltage, corrosive chemical, certain moving parts of a machine, etc.). In the event of collision with a machine frame, it is the victim's movement energy at the moment of impact and the characteristics of the machine frame (deformability, shape) that will cause injury. Under these circumstances, most of Haddon's strategies cannot be implemented for two reasons. First, the energy causing the injury is not external to the victim but conveyed by him or her. Hence, the strategy that involves "separating in time and space the energy source from the vulnerable target" cannot be applied. Second, interactions with the machine cannot be eliminated because they are inherent to the work itself. While dedicated to personal accidents, Haddon's strategies are usually unsuited to risks arising from movements at work, while the latter represent the majority of the accident risks to which persons at work are exposed (Leclercq, Cuny-Guerrier et al. 2015). These strategies do nevertheless determine the common representations of occupational accidents as involving energy external to man. Indeed, according to Hovden, Albrechtsen et al. (2010), "there seems to be little need for new models and approaches for the sake of understanding the direct causes of occupational 
accidents in daily work at the sharp end. For this purpose, Gibson's basic energy-barrier model and Haddon's 10 strategies for loss prevention will never be outdated".

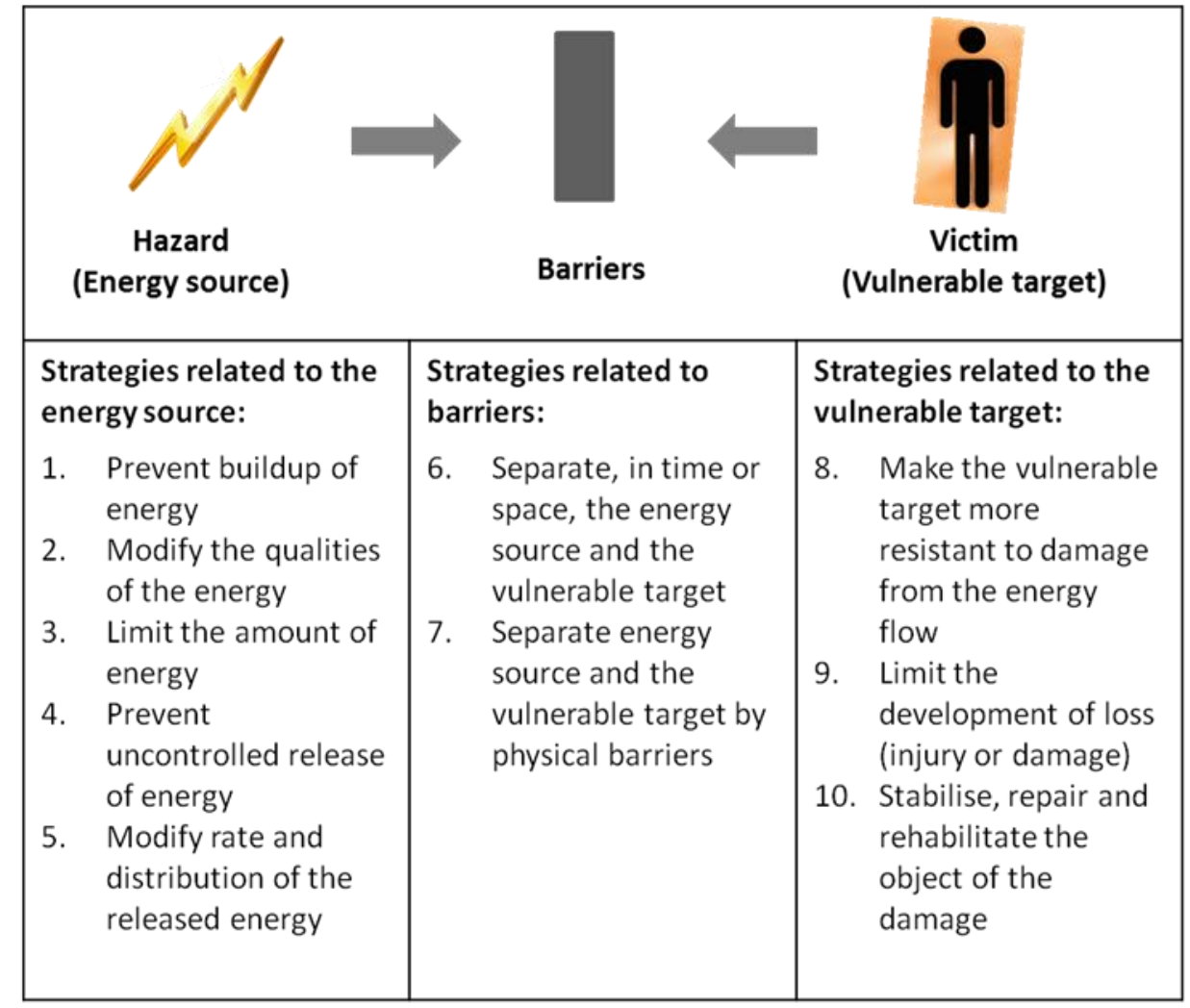

Figure 4. Haddon's 10 accident prevention strategies.

Source. Kjellen (2000), adapted from (Haddon 1980)

Haddon's strategies are not the only barriers that prevent damage. Hollnagel $(2004 ; 2008)$ describes precisely this broad concept of barrier. It can be as much a safety cover or guard-rail as any mean or rule intervening at any stage in the genesis of the damage to stop it. Barriers can be physical, functional or symbolic. The efficiency of physical and functional barriers like Haddon's strategies which intervene at a level close to the damage in its genesis is the highest. However they are difficult, if impossible, to implement when injury is produced by the victim's movement energy.

\subsection{LINK BETWEEN PERSONAL ACCIDENT AND PROCESS}

Hopkins (2009) observed that personal safety hazards may have little to do with the processing activity of the plant. If we limit accident consideration to the content of Figure 3, the relationship between the energy/hazard and the technological process only appears 
explicitly when the injury causing energy is specific to process operation. The link between personal accidents and process is therefore not that simple, as Kjellén (2009) suggests. It is even more unclear when in-depth analysis of personal movement disturbances during work reveals contributing factors that involve the overall production process, e.g. safety management (Bentley and Haslam 2001), equipment usage (Kines 2003), work organisation (Leclercq and Thouy 2004) or work system design (Derosier, Leclercq et al. 2008). Contributing factors of the same type would therefore explain both personal and process accidents. However, in keeping with Hale (2002), we can assume that singular factors (although of the same nature) and their accident causing combinations differ depending on the type of energy affected by the loss of control.

If a personal accident damages neither the company installations nor the external environment, we cannot ignore its indirect consequences on company operation: the need to replace the victim, the added workload temporarily allocated to his/her colleagues, possible production stoppage and disorganisation, additional workload (care, declaration, management, analysis, etc.), and other negative effects. These consequences contribute to creating a fertile breeding ground for any type of process or personal accident to occur at the company.

\subsection{COMPROMISES AND REGULATIONS TO COPE WITH PRODUCTION AND SAFETIES.}

Bellamy (2015) notes that "failure to control body balance" is the prime safety barrier failure on the basis of 963 scaffold occupational accidents. This means that the worker could not perform the job while controlling his movement. The author also notes that safety barrier failures result from a lack of motivation/awareness in relation to workplace safety and from the fact that the main goal would seem to be getting the job done (conflict resolution failure). Regulations are implemented at every level of the sociotechnical system (as far as service beneficiaries, if applicable) for managing production and the different risks. This is reflected by the 2005 BP Texas City Plant explosion analysis, which revealed a high level of occupational safety but less attention to process-related signals. At the sharp end (work situations), we also observe that the worker invariably makes compromises between production/production safety and his/her personal safety - controlling his/her movement in this case (Leclercq, Thouy et al. 2007).

Regulations and compromises embody the need to integrate process and personal energy control. Integration implies integration of goals adopted for managing process and personal safety. In the former, management is intended to prevent potential damage due to losing 
process control; this damage can affect or not affect those involved in process operation. In the latter, management is intended to preserve operators contributing directly or indirectly to process operation from bodily damage. The proposed model is useful for this purpose and so for further field studies and methodological developments focusing on the control of both process and personal energies.

\section{CONCLUSION}

This paper presents a proposed damage production model in the event of an accident occurring in a sociotechnical system, whether this is a personal or process accident. The suggested model distinguishes damage production energies that are external to man and specific to process operation from energies that are conveyed by man, i.e. energy from human movements when working. It is the energy external to man that produces the damage in process accidents. On the other hand, it is the energy of the victim's movements that produces the damage in most personal accidents; energy that most often threatens only the victim himself or herself, if control is lost.

This damage production model highlights many occupational accidents, in which the type of hazard/energy heavily curtails the potential for installing the most efficient preventive barriers. The model formalising the coexistence of hazards/energies of fundamentally different types could be a useful tool to progress in integrating control of process and personal energies. This integration appears indeed necessary in view of the regulations and compromises encountered between production, process safety and personal safety.

Accidents are not limited to damage production, which also emphasises the need to pursue model development further upstream in the damage genesis.

Acknowledgements. The authors wish to thank Corinne Grusenmeyer for her receptiveness, reading recommendations and proofreading, all of which have significantly shaped the present paper. They also thank the late Michel Monteau, occupational safety researcher at the INRS and Xavier Cuny, CNAM Honorary Professor of Hygiene and Safety, without whom the model of an accident with movement disturbance, which underpins development of our proposed model, could not have been developed 
References

Bellamy, L. J. (2015). "Exploring the relationship between major hazard, fatal and non-fatal accidents through outcomes and causes." Safety Science 71, Part B: 93-103.

Bellamy, L. J., M. Mud, et al. (2013). "Analysis of underlying causes of investigated loss of containment incidents in Dutch Seveso plants using the Storybuilder method." Journal of loss prevention in the process industries 26(6): 1039-1059.

Bentley, T. A. and R. A. Haslam (2001). "Identification of risk factors and countermeasures for slip, trip and fall accidents during the delivery of mail." Applied Ergonomics 32(2): 127-134.

Bragatto, P. A., S. M. Ansaldi, et al. (2015). "Small enterprises and major hazards: How to develop an appropriate safety management system." Journal of loss prevention in the process industries 33: 232-244.

Carayon, P., P. Hancock, et al. (2015). "Advancing a sociotechnical systems approach to workplace safety - developing the conceptual framework." Ergonomics 58(4): 548564.

Derosier, C., S. Leclercq, et al. (2008). "Studying work practices: a key factor in understanding accidents on the level triggered by a balance disturbance." Ergonomics 51(12): 1926-1943.

Fahlbruch, B. and B. Wilpert (2001). La notion de sécurité systémique : un nouveau domaine de recherche pour la psychologie industrielle. Organiser la fiabilité. M. Bourrier. Paris, L'Harmattan: 107-142.

Gauvin, C., A. Lan, et al. (2015). "Chutes, heurts et autres perturbations du mouvement : L'expérience du Québec : portrait statistique, actions de prévention et recherches menées par l'IRSST " Hygiène et Sécurité du Travail 239: 40-43.

Gibson, J. (1961). The contribution of experimental psychology to the formulation of the problem of safety. A brief for basic Research. Behavioral approaches to accident research. A. f. t. a. o. c. children.

Grote, G. (2012). "Safety management in different high-risk domains - All the same?" Safety Science 50(10): 1983-1992.

Haddon, W. (1973). "Energy Damage and the Ten Countermeasure Strategies." Human Factors: The Journal of the Human Factors and Ergonomics Society 15(4): 355-366.

Haddon, W. (1980). "The basic strategies for preventing damage from hazards of all kinds." Hazard Prevention September/October: 8-12.

Hale, A. (2002). "Conditions of occurrence of major and minor accidents. Urban myths, deviations and accident scenario's." Tijdschrift voor toegepaste Arbowetenschap 15(3): 34-41.

Hollnagel, E. (2004). Barriers and Accident Prevention, or how to improve safety by understanding the nature of accidents rather than finding their causes. Hampshire (United KIngdom).

Hollnagel, E. (2008). "Risk+barriers=safety?" Safety Science 46(2): 221-229.

Hopkins, A. (2009). "Thinking About Process Safety Indicators." Safety Science 47(4): 460465.

Hovden, J., E. Albrechtsen, et al. (2010). "Is there a need for new theories, models and approaches to occupational accident prevention?" Safety Science 48(8): 950-956.

Hoyos, C. G. (1980). Psychologische Unfall und Sicherheitsforschung. Stuttgart, Kohlhammer.

ICECI (International classification of external causes of injuries) (2004). Consumer Safety Institute. Amsterdam and AIHW National Injury Surveillance Unit, Adelaide. 
IRGC (International Risk Governance Council ) (2005). White paper on risk governance. Towards an integrative approach. IRGC, Geneva.

Kines, P. (2003). "Case studies of occupational falls from heights: Cognition and behavior in context." Journal of Safety Research 34(3): 263-271.

Kjellén, U. (2000). Prevention of accidents through experience feedback. London (United Kingdom), CRC Press (Taylor and Francis Group).

Kjellén, U. (2009). "The safety measurement problem revisited." Safety Science 47(4): 486489.

Koehler, K. A. and J. Volckens (2011). "Prospects and Pitfalls of Occupational Hazard Mapping: 'Between These Lines There Be Dragons'." Annals of Occupational Hygiene 55(8): 829-840.

Le Bouar, G. and Chauvin, C. (2006). "Example of the dockside accident risk". International maritime health 57(1-4):103-113.

Leclercq, S. (2016). Hazard concept and falls. Fall Prevention and Protection: Principles, Guidelines, and Practices. H. Hsiao. Boca Raton, FL 33487, CRC Press Taylor and Francis Group.

Leclercq, S., A. Cuny-Guerrier, et al. (2015). "Similarities between work related musculoskeletal disorders and slips, trips and falls." Ergonomics 58(10): 1624-1636.

Leclercq, S., M. Monteau, et al. (2010). "Avancée dans la prévention des "chutesde plainpied" au travail. Proposition de définition opérationnelle d'une nouvelle classe : "les accidents avec perturbation du mouvement (APM)"." Perspectives interdisciplinaires sur le travail et la santé 12(3).

Leclercq, S., D. Saurel, et al. (2014). "Research into cases of slips, collisions and other movement disturbances occurring in work situations in a hospital environment." Safety Science 68(0): 204-211.

Leclercq, S. and S. Thouy (2004). "Systemic analysis of so-called 'accidents on the level' in a multi trade company." Ergonomics 47(12): 1282-1300.

Leclercq, S., S. Thouy, et al. (2007). "Progress in understanding processes underlying occupational accidents on the level based on case studies." Ergonomics 50(1): 59-79.

Rasmussen, J. and I. Svedung (2000). Proactive risk management in a dynamic society. Karlstad (Sweden): 160 p.

Runyan, C. W. (2003). "Introduction: Back to the Future-Revisiting Haddon's Conceptualization of Injury Epidemiology and Prevention." Epidemiologic Reviews 25(1): 60-64.

Tak, S. and G. M. Calvert (2011). "The estimated national burden of physical ergonomic hazards among US workers." American Journal of Industrial Medicine 54(5): 395-404. 